\title{
PERBANDINGAN VALIDITAS ANALISIS MOYERS DAN ANALISIS SITEPU PADA MAHASISWA SUKU MINANG FAKULTAS KEDOKTERAN GIGI UNIVERSITAS ANDALAS
}

\author{
Monica Wihanda Kurnia ${ }^{1}$, Nur Indrawati Lipoeto ${ }^{2}$, Hidayati ${ }^{1}$ \\ ${ }^{\mathbf{1}}$ Fakultas Kedokteran Gigi Universitas Andalas \\ ${ }^{2}$ Fakultas Kedokteran Universitas Andalas
}

\begin{abstract}
Background: Malocclusion is a deviation from normal occlusion of teeth, and the majority of malocclusion cases occur in the stage of mixed dentition. There are several methods in the analysis of mixed dentition, two of which are Moyers analytical method and Sitepu analytical method. This study aims to determine the comparison of validity between Moyers analysis and Sitepu analysis when used in Minang ethnic students at FKG UNAND. Methods: This study used an analytical descriptive method. The sample consisted of 50 Minang ethnic students at Dentistry Faculty ( FKG) of Andalas University selected by purposive sampling technique. The data analysis used Mann-Whitney test for maxilla and Independent t-test for mandible. Result: The results show the existence of differences in the validity between Moyers analysis and Sitepu analysis if used to Minang ethnic students at FKG UNAND. Sitepu analysis was valid in maxilla and mandible ( $p>0.05$ ), while Moyers analysis was only valid in maxilla ( $p>0.05)$, and in mandible showed the value of $p<0.05$. Conclusion: The conclusion of this study is that there is validity difference between Moyers analysis and Sitepu analysis in Minang ethnic students of FKG UNAND, Sitepu method is valid in maxilla and mandible, while Moyers analysis is only valid in maxilla.
\end{abstract}

Keywords: CPP, four mandibular incisors, Moyers analysis, Sitepu analysis

Affiliasi penulis: ${ }^{1}$ Fakultas Kedokteran Gigi Universitas Andalas Korespondensi: hidayati, email: hidayati@dent.unand.ac.id

\section{PENDAHULUAN}

Maloklusi adalah penyimpangan dari oklusi normal gigi. Maloklusi merupakan salah satu masalah utama yang dihadapi selama perkembangan dento-facial. ${ }^{1}$ Maloklusi bisa terjadi karena adanya malrelasi lengkung gigi atau lengkung rahang dan adanya kelainan pada gigi. Secara garis besar etiologi dari maloklusi dapat dibedakan menjadi dua yaitu factor genetik dan faktor lingkungan. ${ }^{2}$ Kebanyakan dari kasus maloklusi terjadi pada tahapan gigi campuran, dan selama periode kritis ini dokter gigi perlu menentukan diagnosis yang tepat untuk masingmasing maloklusi. ${ }^{3}$

Ketepatan dalam diagnosa adalah langkah pertama dalam keberhasilan perawatan ortodontik. Penggunaan metode analisis yang tidak tepat dapat menghambat rencana perawatan secara keseluruhan, karena kesalahan prediksi jumlah lebar mesiodistal kaninus dan premolar yang belum erupsi dapat mempengaruhi rencana perawatan yang akan dipilih untuk masing-masing kasus, khususnya keputusan mengenai ektraksi gigi. ${ }^{4-5}$

Analisis gigi campuran adalah prediksi jumlah ukuran lebar mesiodistal kaninus, premolar pertama dan 
premolar kedua (sumCPP) yang digunakan untuk menghitung diskrepansi atau selisih antara ruang yang tersedia (available space) dan ruang yang dibutuhkan (required space) di masing- masing kuadran gigi dalam satu rahang.6-7 Ada beberapa metode dalam perhitungan ruang yang dibutuhkan pada pasien gigi campuran, diantaranya dengan dental radiografi, persamaan regresi, serta kombinasi dari keduanya. ${ }^{1,4,6-14}$

Beberapa metode menggunakan tabel prediksi ukuran kaninus dan premolar (pertama dan kedua) berdasarkan hubungannya dengan jumlah lebar mesio-distal insisivus permanen mandibula. Hal ini dikarenakan insisivus permanen mandibula merupakan gigi yang pertama-tama tumbuh pada tahap gigi campuran, jarang terjadi anomali pada bentuk dan ukuran, mudah diukur, dan memiliki korelasi yang kuat dengan kelompok gigi lainnya. ${ }^{5}$

Salah satu metode untuk memprediksi ukuran lebar mesio-distal kaninus dan premolar (pertama dan kedua) permanen pada fase gigi campuran adalah dengan menggunakan table probabilitas Moyers (1958). Tabel ini merupakan tabel yang paling banyak digunakan secara luas karena memiliki beberapa keuntungan: (1) memiliki kesalahan yang minimal (2) bisa digunakan oleh dokter gigi ahli maupun pemula (3) tidak memakan waktu yang lama dalam pengerjaannya (4) tidak membutuhkan gambaran radiografi (5) bisa dipakai untuk gigi rahang atas maupun rahang bawah. ${ }^{3,8-9}$

Meskipun metode analisis Moyers memiliki banyak keuntungan, tapi dalam penelitiannya Moyers menggunakan sampel anak-anak dari ras Kaukasian. Penggunaannya sendiri untuk ras yang berbeda masih dipelajari dan diragukan keakuratannya. ${ }^{3-4,9-10,12,15}$ Hal ini dikarenakan adanya perbedaan ukuran gigi akibat dari perbedaan genetik dan ras, sebagai contohnya metode yang didisain untuk populasi Asia diketahui lebih akurat jika digunakan pada orang-orang Malaysia. ${ }^{16}$ Begitu pula dengan Indonesia. Indonesia dikenal memiliki banyak keragaman suku bangsa, salah satunya adalah suku Minang di Sumatra Barat. ${ }^{17}$ Menurut Koentjaraningrat (1987) suku Minang merupakan bagian dari ras Deutro Melayu. Berdasarkan gelombang kedatangannya, Deutro Melayu merupakan sub-ras yang memasuki Indonesia pada gelombang kedua sekitar 300 sampai 200 SM. Sebelumnya subras Proto Melayu terlebih dahulu masuk ke Indonesia pada 3000 SM. Kedua subras ini pada awalnya berasal dari ras Mongoloid dan Austromelanesid. ${ }^{17}$ 
Sitepu (1983) dalam tesisnya menemukan cara untuk menentukan diskrepansi rahang pada ras Deutro Melayu dalam tahap gigi campuran. Perhitungan ini dilakukan dengan cara membandingkan hasil pengukuran pada empat insisivus permanen mandibula untuk memprediksikan ruang yang dibutuhkan (required space) untuk erupsi gigi kaninus dan premolar (pertama dan kedua) permanen. Metode ini memiliki derajat kepercayaan mencapai $99 \% .^{7}$

Berlandaskan pada pendapat diatas, peneliti ingin mengetahui validitas analisis Moyers dan analisis Sitepu jika digunakan pada mahasiswa suku Minang di Fakultas Kedokteran Gigi Universitas Andalas.

\section{METODE}

Desain penelitian yang digunakan adalah observasional analitik dengan pendekatan cross sectional. Pemilihan sampel dengan cara purposive sampling dengan besar sampel dalam penelitian ini adalah 50 responden.

Pada 50 responden dilakukan pencetakan model studi. Setelah itu dilakukan pengukuran mesio- distal empat gigi insisivus mandibula, serta mesio distal gigi kaninus dan premolar (pertama dan kedua) (CPP) maksila dan mandibula. CPP pada regio kanan maksila dijumlahkan dengan regio kiri maksila, lalu dibagi dua, angka ini dijadikan ukuran lebar mesio- distal CPP untuk maksila. Hal yang sama juga berlaku untuk mandibula. Setelah itu dilakukan prediksi ukuran CPP berdasarkan analisis Moyers dan analisis Sitepu berdasarkan jumlah lebar empat insisivus mandibula.

Setelah pengukuran manual pada model studi dan prediksi dengan analisis Moyers dan analisis Sitepu selesai, hasil yang didapat dimasukkan dalam master tabel, kemudian dilakukan analisis statistik menggunakan uji MannWhitney untuk maksila dan Independent Sample T Test untuk mandibula.

\section{HASIL DAN PEMBAHASAN}

Total dari keempat insisivus mandibula, CPP maksila dan CPP mansibula adalah sebagai berikut:

Tabel 1. Total Insisivus mandibula, CPP maksila, dan CPP mandibula

\begin{tabular}{lcccc}
\hline & $\begin{array}{c}\text { Rerata } \\
(\mathbf{m m})\end{array}$ & SD & $\begin{array}{c}\text { Min } \\
(\mathbf{m m})\end{array}$ & $\begin{array}{c}\text { Max } \\
(\mathbf{m m})\end{array}$ \\
\hline$\sum$ Insisivus Mandibula & 23,3 & 1,20 & 20,57 & 26,61 \\
$\sum$ CPP Maksila & 22,76 & 1,05 & 20,41 & 25,38 \\
$\sum$ CPP Mandibula & 21,73 & 1,06 & 19,26 & 23,84 \\
\hline
\end{tabular}

Menggunakan total ukuran lebar mesio- distal empat insisivus mandibula, didapatkan ukuran prediksi CPP maksila dan mandibula berdasarkan tabel Moyers 75\%. Hasil penjumlahannya berupa rata- rata dan standar deviasi dapat dilihat pada table 2 . 
Tabel 2. Prediksi CPP maksila dan mandibula dengan metode analisis Moyers

\begin{tabular}{lcccc}
\hline $\begin{array}{c}\text { Analisis } \\
\text { Moyers }\end{array}$ & $\begin{array}{c}\text { Rerata } \\
(\mathbf{m m})\end{array}$ & SD & $\begin{array}{r}\text { Min } \\
(\mathbf{m m})\end{array}$ & $\begin{array}{r}\text { Max } \\
(\mathbf{m m})\end{array}$ \\
\hline Maksila & 22,87 & 0,67 & 21,20 & 24,50 \\
Mandibula & 22,34 & 0,72 & 20,70 & 24,30 \\
\hline
\end{tabular}

Menggunakan total ukuran lebar mesio-distal empat insisivus mandibula, didapatkan ukuran prediksi CPP maksila dan mandibula berdasarkan tabel Sitepu. Hasil penjumlahannya berupa rata-rata dan standar deviasi dapat dilihat pada tabel 3 .

Tabel 3. Prediksi CPP maksila dan mandibula dengan metode analisis Sitepu

\begin{tabular}{lcccc}
\hline $\begin{array}{c}\text { Analisis } \\
\text { Sitepu }\end{array}$ & $\begin{array}{c}\text { Rerata } \\
(\mathbf{m m})\end{array}$ & SD & $\begin{array}{c}\text { Min } \\
(\mathbf{m m})\end{array}$ & $\begin{array}{c}\text { Max } \\
(\mathbf{m m})\end{array}$ \\
\hline Maksila & 22,87 & 0,67 & 21,20 & 24,50 \\
Mandibula & 22,34 & 0,72 & 20,70 & 24,30 \\
\hline
\end{tabular}

Perbandingan nilai prediksi metode analisis Moyers dan metode analisis Sitepu dengan diukur secara manual pada model studi dapat terlihat pada tabel 4 .

Tabel 4. Perbandingan Moyers dan Sitepu dengan Manual Model pada RA dan RB

\begin{tabular}{ccccc}
\hline & \multicolumn{2}{c}{ Moyers } & \multicolumn{2}{c}{ Sitepu } \\
& RA & RB & RA & RB \\
\hline Manual & 0,349 & $0,001^{*}$ & 0,091 & 0,519 \\
\hline
\end{tabular}

Analisis pada gigi campuran penting dalam diagnosis dan menentukan rencana perawatan pada kasus maloklusi gigi. Pemilihan metode analisis yang tepat perlu dilakukan agar didapatkan diagnosis dan rencana perawatan yang tepat pula untuk masing- masing maloklusi. Metode analisis Moyers dan metode analisis Sitepu memperlihatkan perbedaan validitas jika digunakan pada ras yang berbeda. Oleh sebab itu, maka penelitian ini dilakukan untuk melihat metode analisis manakah yang lebih valid jika digunakan pada suku Minang yang merupakan bagian dari sub-ras Deutro Melayu.

Dilakukan uji Mann-Whitney untuk menguji validitas antara hasil prediksi menggunakan metode analisis Moyers dan metode analisis Sitepu dengan hasil hitung manual jumlah lebar mesio-distal kaninus dan premolar (pertama dan kedua) pada maksila dan diperolah hasil kedua metode analisis valid jika digunakan pada maksila suku Minang ( $\mathrm{p}>0.05)$, akan tetapi hasil berbeda terlihat dari uji-t yang dilakukan pada mandibula. Terlihat perbedaan validitas, hanya metode analisis Sitepu yang dinyatakan valid pada mandibula suku Minang ( $\mathrm{p}>0.05)$, sedangkan metode analisis Moyers tidak valid jika digunakan pada mandibula suku Minang $(\mathrm{p}<0.05)$.

Terdapat beberapa penelitian yang membandingkan metode analisis Moyers dan metode analisis Sitepu. Dua diantaranya adalah penelitian yang dilakukan oleh Fitiariski (2013) dan penelitian yang dilakukan oleh Saptiari (2011). Kedua penelitian tersebut berkesimpulan bahwa metode alternatif 
yang lebih tepat digunakan pada pasien gigi campuran di RSGM Universitas Jember adalah metode análisis Sitepu. ${ }^{18,19}$

Penelitian yang dilakukan oleh Fitiariski (2013) dengan hasil yang memperlihatkan perbedaan yang signifikan $(\mathrm{p}<0.05)$ pada pengukuran lebar mesio-distal kaninus dan premolar (pertama dan kedua) antara metode radiografi dan Sitepu, dan antara metode radiografi dan Moyers pada maksila. Sedangkan untuk mandibula tidak terdapat perbedaan yang signifikan $(\mathrm{p}>$ 0.05) antara metode radiografi dan Sitepu, akan tetapi untuk metode radiografi dan Moyers memperlihatkan perbedaan yang signifikan $(\mathrm{p}<0.05)$.

Beberapa penelitian untuk menguji validitas dari metode analisis Moyers pada berbagai macam kelompok etnis dan ras yang memiliki hasil sama dengan penelitian ini adalah analisis yang dilakukan di Belgia ${ }^{3}$, Libia ${ }^{6}$, Malay $^{16}$, dan Thailand ${ }^{20}$. Hasil dari penelitian tersebut menyatakan bahwa metode analisis Moyers tidak valid jika digunakan pada kelompok etnis dan ras pada daerah tersebut.

Hasil review dari metode analisis Moyers yang dilakukan oleh Butt, dkk (2012) menyatakan bahwa beberapa penelitian yang dilakukan dengan menggunakan sampel orang-orang Pakistan memperlihatkan bahwa metode analisis Moyers tidak akurat jika digunakan pada populasi tersebut. ${ }^{8}$ Menurut penelitian Dasgupta dan Zahir (2012) yang melakukan uji validitas metode analisis untuk gigi campuran pada masyarakat Bengali mendapatkan hasil bahwa metode analisis Moyers bisa digunakan pada populasi tersebut, akan tetapi perlu dilakukan sedikit modifikasi pada rumus persamaan regresinya. ${ }^{1}$ Penelitian lain yang dilakukan oleh Memon dan Fida (2010) yaitu uji validitas metode analisis Moyers yang dilakukan pada pasien di Aga Khan University Hospital, Karachi, memperlihatkan hasil metode analisis Moyers valid jika digunakan pada sampel wanita dari populasi tersebut. ${ }^{10}$

Hasil dari uji analisis pada penelitian ini dengan menggunakan metode analisis Moyers dan Sitepu yang memperlihatkan adanya perbedaan validitas, berhubungan dengan ukuran lebar mesio- distal gigi sampel yang digunakan. Penelitian ini menggunakan 50 sampel maksila dan mandibula suku Minang, yang mana suku Minang merupakan bagian dari sub-ras Deutro Melayu. Tabel analisis Sitepu merupakan tabel yang dikembangkan dengan menggunakan sampel anak-anak dari ras Deutro Melayu, sedangkan tabel analisis Moyers dikembangkan dari anak-anak ras Kaukasoid. Seperti disebutkan pada beberapa sumber, ras 
merupakan salah satu faktor yang dapat mempengaruhi karakteristik kraniofasial dan lebar mesio-distal gigi. ${ }^{4,15}$ Sehingga diperlukan metode analisis yang tepat untuk masing-masing ras, agar diperoleh diagnosa dan rencana perawatan yang tepat pula untuk masing- masing maloklusi.

Terlihat adanya perbedaan validitas dari metode analisis Moyers dan metode analisis Sitepu dari hasil penelitian-penelitian yang terdahulu. Hal ini dikarenakan tidak ada metode analisis yang akan benar-benar valid untuk memprediksikan ukuran lebar mesio-distal kaninus dan premolar (pertama dan kedua) jika digunakan pada sampel yang berbeda. Setiap prediksi kaninus dan premolar (pertama dan kedua) yang didapat dari metode analisis bisa lebih besar atau lebih kecil dari pengukuran manual pada maksila dan mandibula sampel.

\section{SIMPULAN}

Metode analisis Moyers dan metode analisis Sitepu dapat diterapkan pada suku Minang. Berdasarkan hasil penelitian ini dapat disimpulkan bahwa metode analisis Moyers hanya valid pada maksila, sedangkan metode analisis Sitepu valid pada kedua rahang baik maksila maupun mandibula.

\section{KEPUSTAKAAN}

1. Dasgupta B, Zahir S. Comparison of Two nonradiographic techniques of mixed dentition space analysis and evaluation of their reliability for Bengali Population. Contemp Clin Dent. 2012; 3: 146-50.

2. Rahardjo P. Ortodonti Dasar. Surabaya: Pusat Penerbitan dan Percetakan Unair (AUP); 2012.

3. Sholapurmath SM, Benni DB, Mandroli P. Applicability of Two Mixed Dentition Analysis in Children of Jangam Community of Belgium City. World J Dent. 2012;3(4):324-9.

4. Ajayi E, Azado C. Regression Equation and Probability Tables for Mixed Dentition Analysis in a Nigerian Population. J Dent Health Oral Disord Ther. 2014;1(4):1-8.

5. Galvao MdAB, Dominguez GC, Tormin ST, Akamine A, Tortamano A, Fantini SMd. Applicability of Moyers Analysis in Mixed Dentition: A Systematic Review. Dental Press J Orthod 2013;18(6).

6. Bugaighis I, Karanth D, Elmouadeb H. Mixed Dentition Analysis in Libyan School Children. J Orthodont Sci. 2013;2(4):115-9. 
7. Rahardjo P. Diagnosis

Ortodontik. Surabaya: Pusat

Penerbitan dan Percetakan

Unair; 2008.

8. Butt S, Chaudhry S, Javed M, Wahid A, Ehsan A, Malik S, et al. Mixed Dentition Space Analysis: A Review. Pak Oral Dental J. 2012;32(3):502-7.

9. Buwembo W, Luboga S. Moyer's Method of Mixed Dentition Analysis: A Meta-Analysis. Afr Health Sci. 2004;4(1):63-6.

10. Memon S, Fida M. Comparison of Three Mixed Dentition Analysis Methods in Orthodontic Patient at AKUH. J Coll Physicians Surg Pak. 2010;20(8):533-7.

11. Proffit WR, Henry W. Fields J, Sarver DM. Contemporary Orthodontics. Canada: Mosby Elsevier; 2007.

12. Ngesa JL. Applicability of Tooth Size Predictions in the Mixed Dentition Analysis in a Kenyan Sample. Republic of South Africa: University of the Western Cape; 2004.

13. Felício LG, Ruellas ACdO, Bolognese AM, Sant'Anna EF, Araújo MTdS. Mixed-dentition Analysis: Tomography Versus Radiographic Prediction and
Measurement. Dental Press J

Orthod. 2010;15(5):159-65.

14. Tayyab M, Hussain U, Ayesha, Sumayya, Ayub A. Applicability of Tanaka and Johnston Mixed Dentition Analysis in a Peshawar Sample. Pak Oral Dental J. 2014;34(2):322-5.

15. Hammad SM, Abdellatif AM. Mixed dentition space analysis in Egyptian children. J Pediatr Dent. 2010;20(2):115-21.

16. Mahmoud BK, Asab SHIA, Taib H. Accuracy of Four Tooth Size Prediction Methods on Malay Population. ISRN Dentistry. 2012.

17. Irsa R, Syaifullah, Tjong DH. Variasi Kefalometri pada Beberapa Suku di Sumatra Barat. J Bio UA. 2013;2(2):130-7.

18. Fitiariski I. Perbedaan Pengukuran Lebar Mesiodistal Gigi Kaninus dan Premolar dengan Menggunakan Metode Radiografi, Sitepu dan Moyers di Klinik Ortodonsia RSGM Universitas Jember. Jember: Universitas Jember; 2013.

19. Saptiari D. Perbandingan Prediksi Leeway Space dengan Menggunakan Tabel Moyers dan Tabel Sitepu pada Pasien Usia 810 Tahun yang Dirawat di Klinik Ortodonsia Rumah Sakit Gigi 
dan Mulut Universitas Jember.

Jember: Universitas Jember;

2011.

20. Jaroontham J, Godfrey K. Mixed

Dentition Space Analysis in a

Thai Population. Europh J

Orthod. 2000; 22: 127-7 